VITTI, M.C.D.; KLUGE, R.A.; GALLO, C.R.; MORETTI, C.L.; JACOMINO, A.P. Efeito do momento de sanitização sobre atributos fisico-químicos e microbiológicos de beterrabas minimamente processadas. Horticultura Brasileira, Brasília, v.22, n.4, p.718-721, out-dez 2004.

\title{
Efeito do momento de sanitização sobre atributos fisico-químicos e microbiológicos de beterrabas minimamente processadas
}

\author{
Maria Carolina D. Vitti ${ }^{1,5}$; Ricardo Alfredo Kluge ${ }^{1,6}$; Claudio Rosa Gallo²; Celso Luiz Moretti ${ }^{4}$; Angelo \\ Pedro Jacomino ${ }^{3,6}$ \\ ${ }^{1}$ ESALQ, Depto. Ciências Biológicas, C. Postal 9, 13418-900 Piracicaba-SP; ${ }^{2}$ Depto Agroindústria Alimentos e Nutrição; ${ }^{3}$ Depto de \\ Produção Vegetal; ${ }^{4}$ Embrapa-Hortaliças, 70359-970 Brasília-DF; ${ }^{5}$ Bolsista CAPES. ${ }^{6}$ Bolsista CNPq; E-mail: mcdvitti@esalq.usp.br
}

\section{RESUMO}

Raízes de beterrabas, cv. Early Wonder, foram minimamente processadas e submetidas a tratamentos de sanitização: controle (sem sanitização); sanitização após o corte (padrão); sanitização antes do descascamento e após o corte; sanitização apenas após o descascamento; sanitização antes e após o descascamento; sanitização antes e após o descascamento, e após o corte. Após os tratamentos, o produto foi colocado em bandejas envoltas com filme de PVC e armazenado a $5 \pm 1^{\circ} \mathrm{C}$ e $85 \pm 5 \%$ UR durante 10 dias. Realizou-se análises físico-químicas e microbiológicas durante o armazenamento refrigerado. Não foi detectada a presença de coliformes fecais e Salmonella nos tratamentos com etapa de sanitização. As contagens de coliformes totais e bactérias psicrotróficas e os teores de betacianina e betaxantina foram maiores para beterrabas não sanitizadas. Houve decréscimo nos teores dos pigmentos durante conservação. A sanitização após o descascamento é a mais apropriada para manutenção da qualidade por reduzir a perda de pigmentos e garantir a segurança alimentar do produto, além de evitar o desperdício de cloro.

Palavras-chave: Beta vulgaris L., pigmentos, processamento mínimo, microbiologia.

\section{ABSTRACT}

Effect of the sanitization moment on physicochemical and microbiological attributes of fresh-cut beet roots

Early Wonder beet roots were minimally processed and submitted to sanitization treatments: control (no sanitization); sanitization after cutting (standard); sanitization before peeling and after cutting; sanitization only after peeling; sanitization before and after peeling; sanitization before and after peeling and after cut. After the treatments, the product was placed on trays wrapped in PVC film and stored at $5 \pm 1{ }^{\circ} \mathrm{C}$ and $85 \pm 5 \%$ RH for 10 days. Physicochemical and microbiological analyses were conducted during refrigerated storage. Fecal coliforms and Salmonella were not detected in beet roots that underwent sanitization. Total coliforms and psychotropic bacteria counts, as well as betacyanin and betaxanthin amounts were higher in non-sanitized beet roots. There was a decrease in pigment amounts during storage. Post-peeling sanitization is the most suitable for quality maintenance, as it reduces pigment loss, ensures good food safety standards and avoids chlorine waste.

Keywords: Beta vulgaris L., pigments, minimally processing, microbiology.

\section{(Recebido para publicação em 20 de janeiro de 2004 e aceito em 2 de setembro de 2004)}

$\mathrm{O}^{\mathrm{s}}$ consumo de produtos minimamente processados tem tido considerável aumento nos últimos anos, em função do maior interesse dos consumidores por produtos cada vez mais naturais e convenientes (Durigan e Sargent, 1999), e também pela maior participação da mulher no mercado de trabalho, envelhecimento da população e aumento na importância das refeições coletivas (Moretti, 2001).

O processamento mínimo usualmente descreve um produto fresco, adequadamente descascado, fatiado ou cortado, $100 \%$ comestível, contrastando com as técnicas de processamento convencionais, as quais incluem congelamento, envasamento ou secagem (Bolin e Huxsoll, 1989).

A beterraba vem aumentando em importância entre as hortaliças minimamente processadas no Brasil. Em sua raiz tuberosa a cor vermelho-arroxeada é devido à presença de betalaínas (Kanner et al., 2001). As betalaínas são pigmentos hidrossolúveis e estão divididas em duas classes: betacianina (cor avermelhada) e betaxantina (cor amarelada), caracterizando a coloração típica das raízes. Estes pigmentos, além de fornecerem cor à beterraba, são importantes substâncias antioxidantes para a dieta humana (Kanner et al., 2001).

Um dos principais problemas tecnológicos observados em beterraba é a descoloração do produto minimamente processado. As operações de lavagem, sanitização e enxague, realizadas após o corte, favorecem a perda de betalaínas, que são solúveis em água (Nilson, 1970). Entretanto, estes procedimentos são de suma importância dentro do fluxograma de preparo de beterraba minimamente processada, como forma de reduzir a contaminação microbiana e os riscos de toxinfecções alimentares.

Visando um melhor aproveitamento, a agregação de valor e aumento de conveniência para o consumo, o presente trabalho teve como objetivo estudar diferentes momentos de sanitização e verificar seu efeito na qualidade de beterraba minimamente processada.

\section{MATERIAL E MÉTODOS}

As beterrabas, cv. Early Wonder, colhidas na região de Piracicaba, foram levadas para o laboratório onde foram selecionadas quanto ao tamanho, firmeza, cor e formato, tendo sido descartadas as raízes murchas, com defeitos e com injúrias. Estas foram pré-lavadas em água corrente com o objetivo de retirar as impurezas advindas do campo. A seguir, o material experimental foi separado em seis lotes, com os tratamentos: T1 - sem sanitização, só pré-lava- 
gem (controle); T2 - sanitização após o corte (padrão); T3 - sanitização antes do descascamento e após o corte; T4 sanitização apenas após o descascamento; T5 - sanitização antes e após o descascamento; T6 - sanitização antes e após o descascamento, e após o corte. Em todos os tratamentos a etapa de sanitização foi acompanhada da etapa de enxague.

As etapas de processamento mínimo ocorreram dentro de câmara fria $\left(10 \pm 1^{\circ} \mathrm{C}\right)$ sobre mesa de aço inoxidável devidamente higienizada. Os operadores utilizaram roupas protetoras (botas, aventais, luvas, máscaras e toucas) como parte das condições mínimas de assepsia.

O produto foi descascado mecanicamente por descascadora industrial (Shymsen) com disco abrasivo para retirada da película externa das raízes. As raízes foram imersas em água resfriada $\left(5 \pm 0,5^{\circ} \mathrm{C}\right)$ por 2 minutos visando manter baixa a atividade metabólica do produto. As beterrabas foram submetidas a etapa de corte em forma de retalhos. Utilizando-se uma processadora industrial (Robot Coupe) com disco de $2 \mathrm{~mm}$ de espessura. Após o corte, o material foi sanitizado via imersão por 6 minutos em água clorada ( $200 \mathrm{mg} \mathrm{L}^{-1}$ de cloro ativo), com o objetivo de reduzir riscos de contaminação microbiana e as raízes foram enxaguadas por 1 minuto em água (com $3 \mathrm{mg} \mathrm{L}^{-1}$ de cloro ativo) para a retirada do excesso de cloro. Em seguida as raízes foram centrifugadas em centrífuga doméstica durante $1 \mathrm{mi}$ nuto para a retirada do excesso de água do produto, com velocidade constante equivalente a $800 \mathrm{x} g$. As raízes foram armazenadas a $5 \pm 1^{\circ} \mathrm{C}$ e $85 \pm 5 \%$ UR durante 10 dias, em bandejas de poliestireno expandido (180 g de produto por bandeja), com dimensões $14 \times 20 \mathrm{~cm}$, envoltas em filmes de PVC (policloreto de vinila) com $14 \mathrm{~mm}$ de espessura. Os atributos avaliados foram teor de sólidos solúveis totais, cor, teor de betacianina e betaxantina e de microbiota contaminante.

O teor de sólidos solúveis totais foi quantificado por meio de leitura direta em refratômetro digital (Atago), utilizando-se uma gota de suco da raiz homogeneizada em centrífuga domés- tica e os resultados foram expressos em ${ }^{\circ}$ Brix. A cor foi determinada com colorímetro (Minolta), determinando-se os valores de $\mathrm{L} \mathrm{a}^{*} \mathrm{~b} *$ e calculando-se o índice de cor (IC) pela fórmula $\mathrm{IC}=1000 \mathrm{xa}^{*} / \mathrm{Lxb}^{*}$ (Mazzuz, 1996). Segundo o autor o IC varia de $-20 \mathrm{a}+20$ sendo que quanto mais positivo mais intenso é o vermelho (Mazzuz, 1996). As leituras foram realizadas diretamente sobre o produto minimamente processado. Os teores de betacianina e betaxantina foram quantificados segundo a metodologia adaptada de Nilson (1970), onde $2 \mathrm{~g}$ de amostra previamente congeladas foram maceradas em $5 \mathrm{ml}$ de água destilada. A solução foi colocada em tubetes e centrifugada utilizando-se centrífuga refrigerada (Sorvall) a $4^{\circ} \mathrm{C}(15.000 \mathrm{rpm})$ durante 40 minutos. Num tubo de ensaio foram homogenizados $1 \mathrm{ml}$ do sobrenadante e $24 \mathrm{ml}$ de água destilada. Foram feitas leituras das amostras a $476 \mathrm{~nm}, 538 \mathrm{~nm}$ e $600 \mathrm{~nm}$. Os cálculos foram feitos pelas das seguintes fórmulas: $\mathrm{x}=1,095$ (ac), $y=b-z-x / 3,1$ e $z=a-x$, sendo: $a=$ leitura da amostra $(538 \mathrm{~nm}) ; \mathrm{b}=$ leitura da amostra (476 nm); c= leitura da amostra $(600 \mathrm{~nm}) ; \mathrm{x}=$ absorção de betacianina; $y=$ absorção de betaxantina e $\mathrm{z}=$ absorção de impurezas. Análises microbiológicas foram realizadas no dia do processamento e no $10^{\circ}$ dia de armazenamento. A microbiota contaminante da beterraba minimamente processada foi avaliada pela contagem total de bactérias psicrotróficas, número mais provável (NMP) de coliformes totais e fecais e presença/ ausência de Salmonella. As análises para contagem de bactérias psicrotróficas, segundo a metodologia convencional (Plate count agar-PCA) e para o NMP de coliformes, segundo a Técnicas de Tubos Múltiplos foram realizadas conforme metodologias descritas por Vanderzant e Splittstoesser (1992). Para determinação da presença de Salmonella foi empregada uma metodologia distinta utilizando o Kit rápido '1-2 test', fabricado pela BioControl/USA, conforme descrito por Silva et al. (2001).

$\mathrm{O}$ delineamento experimental utilizado foi inteiramente ao acaso em esquema fatorial $6 \times 6$ (6 tratamentos e 6 períodos de avaliação) para as análises físico-químicas. Utilizaram-se 4 repeti- ções com aproximadamente $180 \mathrm{~g}$ de raízes minimamente processadas. Os resultados das análises físico-químicas foram submetidos a análise da diferença mínima significativa em teste de comparações múltiplas, onde as diferenças entre dois tratamentos maior que a soma de dois desvios padrões foram consideradas significativas a $5 \%$ de probabilidade (Shamaila et al., 1992).

Para avaliação dos padrões microbiológicos os resultados foram expressos em unidades formadoras de colônias/g (UFC/g) de produto para bactérias psicrotróficas, $\mathrm{NMP} / \mathrm{g}$ de produto para coliformes totais e fecais e presença ou ausência de Salmonella em 25 $\mathrm{g}$ de produto.

\section{RESULTADOS E DISCUSSÃO}

As beterrabas minimamente processadas do controle apresentaram os maiores teores de sólidos solúveis, enquanto as raízes minimamente processadas, que tiveram pelo menos uma sanitização após o corte, apresentaram valores menores de sólidos solúveis (Figura 1a). Estas diferenças ocorreram em função da menor relação superfície/volume de corte das raízes com a água, o que fez extravasar mais conteúdo celular, incluindo os carboidratos solúveis (componente dos sólidos solúveis) que se dissolveram na água de sanitização.

As beterrabas minimamente processadas controle apresentaram os maiores valores de índice de cor (IC), durante o período de armazenamento (Figura 1b). A maior intensidade de coloração das raízes minimamente processadas foi verificada nos tratamentos que não sofreram sanitização após a etapa de corte. Isto já era esperado, considerando que os pigmentos de betalaínas, que são solúveis em água, não entraram em contato com a mesma. Em todos os tratamentos houve uma redução gradativa nos valores de IC com o decorrer do período de armazenamento, devido à descoloração superficial do produto.

$\mathrm{O}$ teor de betaxantina foi maior durante todo armazenamento para beterrabas controle (Figura 1c). Raízes minimamente processadas dos tratamentos com pelo menos uma sanitização após o corte apresentaram os menores 
Tabela 1. Número mais provável de coliformes totais e coliformes fecais e contagem total de bactérias psicrotróficas de beterrabas minimamente processadas submetidas a diferentes momentos de sanitização e armazenadas a $5 \pm 1{ }^{\circ} \mathrm{C}$ e $85 \pm 5 \%$ UR. Piracicaba, ESALQ, 2003.

\begin{tabular}{lcccccc}
\hline \multirow{2}{*}{ Tratamentos } & \multicolumn{2}{c}{ Coliformes totais $^{(1)}$} & \multicolumn{2}{c}{ Coliformes fecais $^{(2)}$} & \multicolumn{2}{c}{ Bactérias psicrotróficas $^{(3)}$} \\
\cline { 2 - 7 } & $\mathbf{0}$ dia & $\mathbf{1 0}$ dias & 0 dia & $\mathbf{1 0}$ dias & $\mathbf{0}$ dia & $\mathbf{1 0}$ dias \\
\hline T1= Controle & $>110$ & $>110$ & 0,36 & 0,91 & $1,59 \times 10^{3}$ & $3,80 \times 10^{5}$ \\
T2= Padrão & 0,91 & 46 & $<0,3$ & $<0,3$ & $2,30 \times 10^{2}$ & $2,36 \times 10^{4}$ \\
T3= Antes do descascamento e após o corte & 0,91 & 46 & $<0,3$ & $<0,3$ & $2,65 \times 10^{2}$ & $2,26 \times 10^{4}$ \\
T4= Após o descascamento & 2,8 & 46 & $<0,3$ & $<0,3$ & $4,14 \times 10^{2}$ & $6,70 \times 10^{4}$ \\
T5= Antes e após o descascamento & 1,5 & 46 & $<0,3$ & $<0,3$ & $4,42 \times 10^{2}$ & $6,24 \times 10^{4}$ \\
T6= Antes e após o descascamento, e após o corte & 0,91 & 46 & $<0,3$ & $<0,3$ & $2,01 \times 10^{2}$ & $2,14 \times 10^{4}$ \\
\hline
\end{tabular}

${ }^{(1)}$ Os resultados obtidos representam o NMP de coliformes totais/g de produto; ${ }^{(2)}$ Os resultados obtidos representam o NMP de coliformes fecais/g de produto; ${ }^{(3)} \mathrm{Os}$ resultados obtidos representam a quantidade de UFC/g de produto.

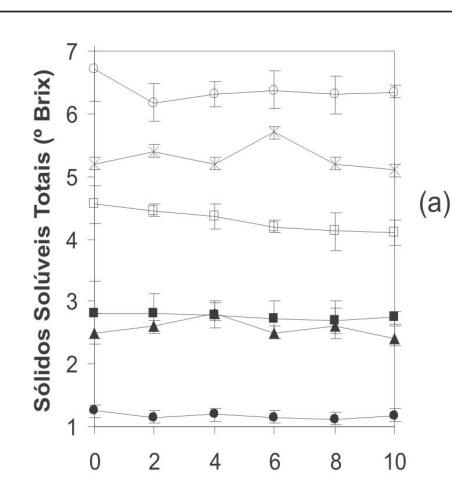

(a)

(b)
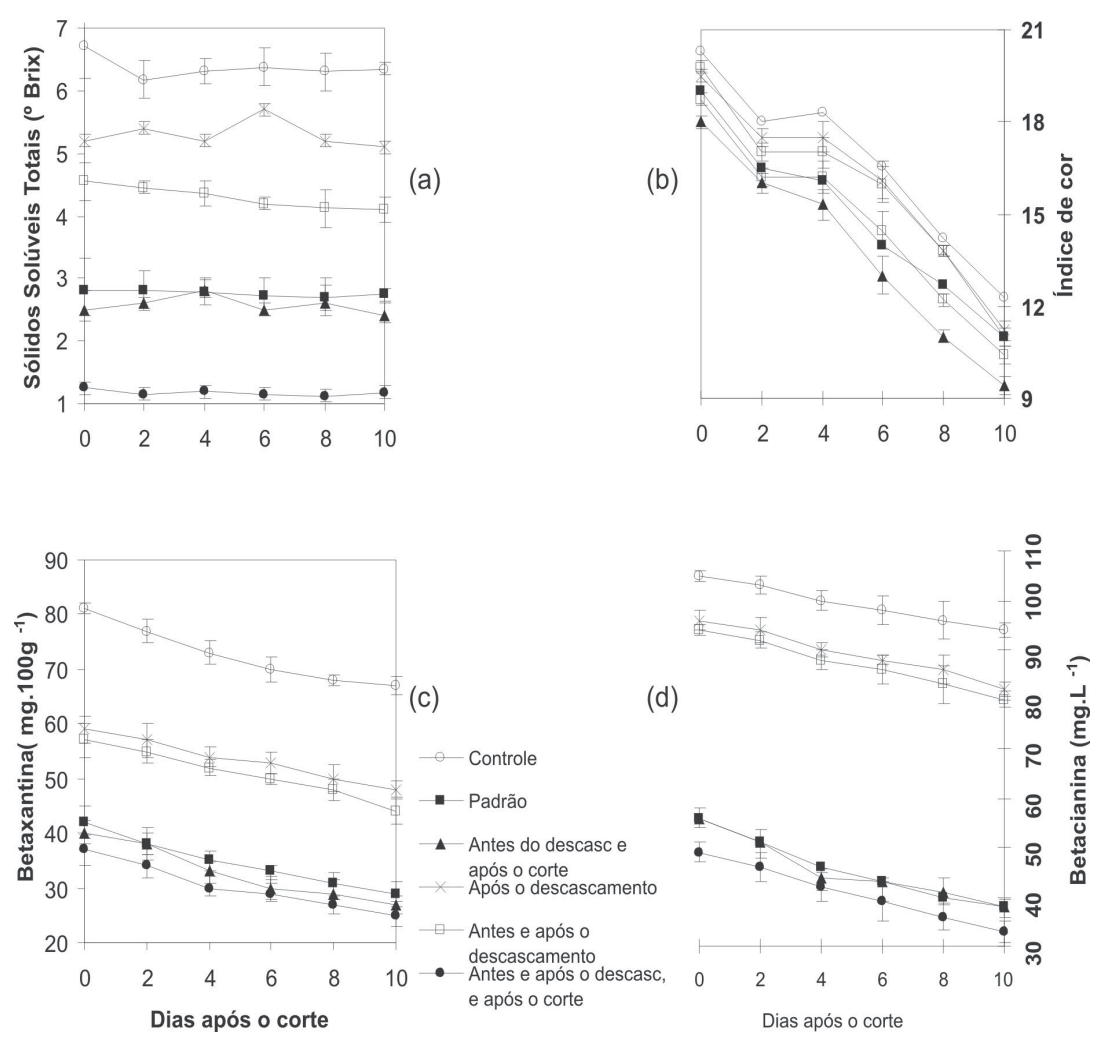

(c)

(d)

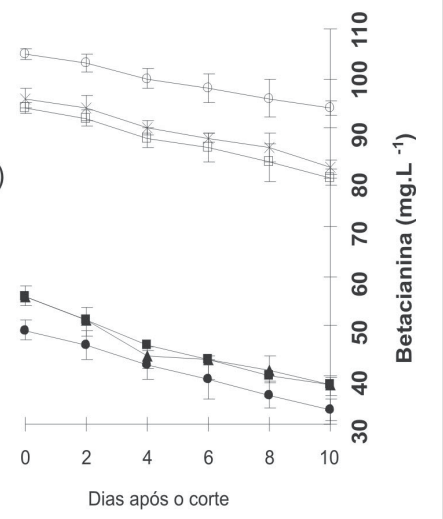

Figura 1. Teor de sólidos solúveis totais (a), índice de cor (b) e teores de betaxantina (c) e teor de betacianina (d) em beterrabas minimamente processadas submetidas a diferentes momentos de sanitização e armazenadas a $5 \pm 1^{\circ} \mathrm{C}$ e $85 \pm 5 \%$ UR. Os valores são médias de 4 repetições, separados pela diferença mínima significativa por Fisher's. Piracicaba, ESALQ, 2003.

valores e não diferiram significativamente entre si durante o experimento.

$\mathrm{O}$ teor de betacianina teve comportamento semelhante ao teor de betaxantina. As beterrabas do controle obtiveram os maiores valores no teor de betacianina durante o armazenamento. Raízes minimamente processadas dos tratamentos com pelo menos uma sanitização após o corte apresentaram os menores valores e não diferiram significativamente entre si durante o experimento (Figura 1d).
Poucos estudos referentes aos teores de pigmentos em beterraba são encontrados na literatura. Sapers e Hornstein (1979) verificaram diferenças significativas no conteúdo de betacianina e betaxantina em diferentes cultivares de beterraba de mesa. $\mathrm{O}$ teor de betacianina e betaxantina em beterraba varia de 45 a

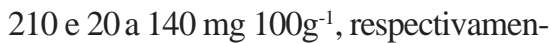
te, dependendo da cultivar (Nilson, 1973).

De maneira geral, foi observado uma perda gradual de pigmentos de betaxantina e betacianina durante o armazenamento (Figuras 1c e 1d), concordando com os resultados obtidos por Osornio e Chaves (1998), os quais verificaram em beterrabas raladas e armazenadas a $0^{\circ} \mathrm{C}$ que o teor de betalaína decresceu aproximadamente 40-50\% após 7 dias. Os pigmentos de betalaínas são mais solúveis em água do que em álcool (Nilson, 1970). No caso de beterrabas minimamente processadas, os processos de sanitização e enxagüe favorecem uma maior perda destes pigmentos devido o contato da superfície das raízes com a água.

Não foi detectada a presença de Salmonella em nenhum dos tratamentos analisados durante o armazenamento. Tais resultados colocam as amostras analisadas em acordo com a Resolução RDC No 12 de 02 de janeiro de 2001, da Agência Nacional de Vigilância Sanitária (ANVISA, 2001) do Ministério da Saúde, que estabelece para hortaliças in natura a ausência de Samonella (em $25 \mathrm{~g}$ de produto) visando a preservação da saúde pública.

A contagem de coliformes totais no dia do processamento foi maior para beterrabas controle, atingindo valores $>110 \mathrm{NMP} / \mathrm{g}$ de produto em ambos os dias de análise (Tabela 1). Para os tratamentos em que pelo menos uma sanitização ocorreu após o corte das raízes, a contagem inicial de coliformes totais foi $0,91 \mathrm{NMP} / \mathrm{g}$ de produto. Foi verificado no $10^{\circ}$ dia de armazenamento, quando todos os tratamentos atingiram nota limite de comercialização, que as beterrabas dos tratamentos que sofreram a operação de sanitização apresentaram contagens de coliformes totais na ordem de $46 \mathrm{NMP} / \mathrm{g}$ de produto (Tabela 1). 
Em nenhuma das amostras de beterrabas que foram submetidas a pelo menos uma etapa de sanitização houve detecção de coliformes fecais (Tabela 1). $\mathrm{Na}$ metodologia de tubos múltiplos, quando aparece o resultado $<0,3 \mathrm{NMP} /$ g significa que nenhum dos tubos inoculados se mostrou positivo.

Para produtos minimamente processados, ainda não existe uma legislação determinando os limites de contagens permitidas. Entretanto, estes resultados estão de acordo com a resolução RDC $\mathrm{n}^{\circ} 12$ de 02 de janeiro de 2001 da ANVISA, que estabelece como padrão o máximo de $10^{2} \mathrm{NMP}$ de coliformes fecais/g de hortaliça fresca.

A contagem total das bactérias psicrotróficas aumentou com o decorrer dos dias de armazenamento para todos os tratamentos (Tabela 1). As beterrabas controle apresentaram as maiores contagens de bactérias psicrotróficas em ambos os dias de análise. Para os tratamentos onde pelo menos uma etapa de sanitização ocorreu após o corte, verificou-se os menores valores de contagens para bactérias psicrotróficas. $\mathrm{O}$ aumento na população de bactérias psicrotróficas também foi verificado em repolhos minimamente processados, de $10^{2}$ para $10^{5} \mathrm{UFC} / \mathrm{g}$ nas amostras mantidas a $4^{\circ} \mathrm{C}$, após o quarto dia de armazenamento (Piagentini et al., 1997).

Embora não existam, na legislação brasileira vigente, padrões para bactérias psicrotróficas totais e coliformes totais, no que diz respeito à quantidade de microrganismos presentes em um alimento, pode-se afirmar que quantidades elevadas $\left(>10^{5} \mathrm{UFC} / \mathrm{g}\right)$ são completamente indesejáveis, em razão do risco do alimento estar estragado, perda real ou potencial das qualidades organolépticas, comprometimento da aparência do alimento e presença de microorganismos patogênicos e/ou deterioradores (Caruso e Camargo, 1984). No presente trabalho, somente as amostras de beterrabas controle com 10 dias de armazenamento, apresentavamse com valores nessa referida ordem.

A implantação de um sistema efetivo de controle, por meio do programa de Análise de Perigo e Pontos Críticos de Controle, é fundamental para o conhecimento e prevenção da contaminação e do crescimento microbiano em produtos minimamente processados (Vanetti, 2000).

Os resultados obtidos mostraram uma redução gradativa na coloração das raízes durante o armazenamento para todos os tratamentos, devido à degradação dos pigmentos. Os tratamentos onde pelo menos uma etapa de sanitização ocorreu após o corte apresentaram-se com coloração vermelho menos intenso do que os demais.

Os resultados obtidos nas análises microbiológicas de todos os tratamentos estão dentro do padrão aceitável pela legislação brasileira em vigor para hortaliças frescas. O tratamento controle, embora tenha apresentado bons resultados, não é recomendado, pois a etapa de sanitização é essencial e indispensável para produtos minimamente processados como forma de reduzir a contaminação microbiana. Portanto, concluise que o momento ideal indicado para sanitizar beterrabas minimamente processadas é após o descascamento, onde a perda de cor e pigmentos é menor em relação ao controle, e as contagens microbiológicas obtidas estão dentro do padrão vigente. Mesmo o tratamento com sanitização após o descascamento não tendo diferido significativamente do tratamento com sanitização antes e após o descascamento, ele apresenta a vantagem de economia de cloro, pois somente um momento de sanitização é suficiente para obter-se um produto com qualidade e segurança alimentar.

\section{AGRADECIMENTOS}

À FAPESP pelo suporte financeiro.

\section{LITERATURA CITADA}

AGÊNCIA NACIONAL DE VIGILÂNCIA SANITÁRIA. Resolução - RDC n ${ }^{\circ} 12$, de 2 de janeiro de 2001. Disponível em: <www.anvisa.gov.br/ legis/resol/12_01rdc.htm>. Acesso em $21 \mathrm{fev}$. 2002.
BOLIN, H.R.; HUXSOLL, C.C. Storage stability of minimally processed fruit. Journal of Food Processing and Preservation, v.13, p.281-292, 1989.

CARUSO, J.G.B.; CAMARGO, R. Microbiologia de alimentos. In: CAMARGO, R. (Ed.). Tecnologia dos produtos agropecuários-alimentos. São Paulo: Nobel, 1984. p.35-49.

DURIGAN, J.F.; SARGENT, S.A. Uso de melão Cantaloupe na produção de produtos minimamente processados. Alimentos e Nutrição, v.10, p.6977, 1999.

KANNER, J.; HAREL, S.; GRANIT, R. Betalains: a new class of dietary cationized antioxidants. Journal of Agricultural and Food Chemistry, v.49, n.11, p.5178-5185, 2001.

MAZZUZ, C.F. Calidad de frutos cítricos: manual para su gestion desde la recoleccion hasta la expedicion. Barcelona: Ed. de Horticultura, 1996. 44 p.

MORETTI, C.L. Processamento mínimo de hortaliças: tendências e desafios. Horticultura Brasileira, Brasília, v.19, n.2, p.172, 2001.

NILSON, T. Studies into the pigments in beetroot (Beta vulgaris L. ssp. vulgaris var. rubra L.). Lantbrukhogskolans Annaler, v.36, p.179-219, 1970.

NILSON, T. The pigment content in beetroot with regard to cultivar, growth, development and growing conditions. Swedish Journal of Agriculture Research, v.3, n.4, p.187-200, 1973. OSORNIO, M.M.L.; CHAVES, A.R. Quality changes in stored raw grated beetroots as affected by temperature and packaging film. Journal of Food Science, v.63, n.2, p.270-330, 1998.

PIAGENTINI, A.M.; PIROVANI, M.E.; GUEMES, D.R. Survival and growth of Salmonella hadar on minimally processed cabbage as influencied by storage abuse conditions. Journal of Food Science, v.62, n.3, p.616-618, 1997.

SAPERS, M.G.; HORNSTEIN, J.S. Varietal differences in colorant properties and stability of red beet pigments. Journal of Food Science, v.44, p.1242-1245, 1979.

SHAMAILA, M.; POWRIE, W.D.; SKURA, B.J. Sensory evaluation of strawberry fruit stored under modified atmosphere packaging (MAP) by quantitative descriptive analysis. Journal of Food Science, v.57, p.1168-1172 and 1184, 1992.

SILVA, N.; JUNQUEIRA, V.C.A.; SILVEIRA, N.F.A. Manual de métodos de análise microbiológica de alimentos. 2.ed. São Paulo: Livraria Varela, 2001. 317 p.

VANETTI, M.C.D. Controle microbiológico e higiene no processamento mínimo. In: ENCONTRO NACIONAL SOBRE PROCESSAMENTO MÍNIMO DE FRUTAS E HORTALIÇAS, 2., Viçosa, 2000. Palestras. Viçosa: Universidade Federal de Viçosa, 2000. p.44-52.

VANDERZANT, C.; SPLITTSTOESSER, D.F. Compendium of methods for the microbiological examination of foods. 3ed. Washington: APHA, 1992. 1219 p. 